\title{
Language Comparison Between Swahili and Malay Languages with Semantic and Pragmatic Problems
}

\author{
Shintia Dwi Putri \\ Department of English Education, Universitas Lancang Kuning, Indonesia \\ dwiputrishintia@gmail.com
}

\begin{abstract}
ARTICLE HISTORY
Received : 2020-04-21

Revised : 2020-04-26

Accepted : 2020-04-27
\end{abstract}

\section{KEYWORDS}

Language comparison

Swahili

Malay

Semantics

Pragmatics

\begin{abstract}
The purpose of this study is to explore the similarities and differences of Malay and Kiswahili, which is better known as Swahili. This study intends to investigate the patterns of response from Malays and Kiswahili. In discussing the idea of linguistic meaning by comparing the Swahili language with Malay, this study focuses on different meanings, assuming that there will be differences regarding the discussion of meaning types that can enhance understanding and appreciation of linguistic meaning. The discussion takes a general conceptual orientation of approach that considers language to be an analysis where the analytical unit is speech acts. From a broader perspective, this article distinguishes the conceptual and associative meaning of the use of Malay and Swahili languages then begins dealing with the individual types. There are five types of meanings discussed, namely conceptual, connotative, social, affective and collocative. The results show that there are many differences between Malay and Swahili languages. The connotation is meaning that is still difficult to understand, and it is what requires the continuation of learning semantics and pragmatics because every language has a different meaning following the culture.
\end{abstract}

\section{Introduction}

A human being is a social creature. In fact, man is a receiver and sender of messages who assembles and distributes information (Greimas, 1970). Sapir (1956) insists that "every cultural pattern and every single act of social behaviour involves communication in either an explicit or implicit sense" (p. 104). The tool for this communication is language (Derin, Putri, Nursafira, Hamuddin, 2020). Greimas (1970) and Sapir (1956) seek to investigate the relationship between language and culture, and what the connection between language and culture is. In other words, if there is a relationship between language and culture, how can they have this association? To achieve the answer, some of the main relevant points are introduced and discussed as follows

The definition of linguistic meaning is complex and thus, somewhat troublesome. The diverse approach to analysis, explanation and interpretation demonstrates this issue (Hamsa \& Weda, 2019), more so considering how easily people create new words and apply new meanings for existing words (Derin, Deliani, Fauziah, Afifah, \& Hamuddin, 2019; Klymenko, 2019). Scholars approach linguistic meaning, in different ways, in particular: as a reference and a context, a brain-image term, a proposition of truth-value or a communicative usage (Kempson, 1977).
Swahili (or Kiswahili as it is called when one is speaking the language) is the most important and widely studied indigenous language of Africa, the National and official language of Kenya and Tanzania (Stigand, 2013). It is spoken as a native language on the eastern coast of Africa and the islands adjacent to the coasts of Kenya and Tanzania from southern Somalia in the north. It is also a Lingua franca of the African Continent spoken as a second language by millions of people mainly in Kenya, Tanzania, Uganda, and East Zaire. In Mozambique, Rwanda, Burundi, Zambia, Malawi, the countries of Southern Arabia including Yemen and Oman and in other parts of the world, they are also speakers.

All speakers of Swahili share a unique way of expressing time, day or night. Two focal points used to say time are sunrise or sunset. The first hour of the day is after dawn, not midnight, and after sunset, the first hour of the night is. The way they communicate indirectly with each other using the popular language, also known as leso, is also peculiar to Swahili speakers. This multifunctional towel typically has a title which sends a proverbial message to its target audience. While to understand the development of the Malaysian languages, in particular the national language, some background issues need to be explained. The term, Bangsa Malaysia coined by Tun Dr. Mahathir, the former prime minister for 22 years, was used to 
emphasize a united Malaysian nation which does not distinguish its citizens according to ethnicity. It is regarded as "people being able to identify themselves with the country, speaking Bahasa Malaysia and accepting the Constitution" (Abdoolcarim, 2000).

The Malay language is Malaysia's official language, and it is one of the Malayo-Polyne-Sian languages; branches of the Austronesian language family spoken widely in Brunei, Indonesia, Malaysia and other neighbouring regions. To Malay, Bahasa Jiwa Bangsa, or language, is the soul of the nation. Through the efforts of national education and cultural assimilation, the Malaysian, Chinese and Indians also can communicate fluently in the Malay language (Fontaine \& Richardson, 2005; Gabriel, 2014; Ozóg, 1993). The Malay language is now written in the 26-letter Roman alphabet due to the influence of British colonization over the Malay Peninsula since 1795. Thus, modern Malay is easy to acquire, thanks to the high abundance and accessibility of ways to learn languages in the twenty-first century's technological era (Asril \& Wiza, 2017; Junaidi, Hamuddin, Simangunsong, Rahman, \& Derin, 2020). Some of the modern Malay words have adopted English vocabulary for word or vocabulary. That is difficult to translate into Malay, such as a hobby, manipulating (manipulation), criteria, etc.

\section{Method}

This qualitative study employs descriptive analysis (Zook \& Pierce, 2018) to reveal the similarities and differences between Malay and Swahili languages. The researcher focused on the semantics and pragmatics, which is focused in particular attention on different meanings, assuming that there will be differences regarding the discussion of the type of meaning can enhance understanding and appreciation of linguistic meaning (Mwihaki, 2004).

The discussion takes a general conceptual orientation of the approach (Cronin, 2016), which considers meaning as use, where the unit of analysis is speech acts. This study distinguished the conceptual and associative meaning of the use of Malay and Swahili languages then begins dealing with the individual types. The researcher also used various references from related articles and books to support the explanation.

\section{Findings and Discussion}

\subsection{Meaning as Use}

Meaning as use is the word of the speaker and particularly the purpose of the speaker or the desired communication effect of the voice. This approach to the idea of meaning is reinforced by the assumption that language is purposeful: we want concrete goals to be fulfilled when we speak. The use of language thus means choosing acceptable linguistic types for the subsequent communicative environment and cultural contexts. Analysis as a practice does not apply explicitly to the meaning or expression per se. it depends on the language, which describes an utterance in terms of the speech act. A speech act has three definitive criteria: locutionary act, illocutionary force and a perlocutionary event. These criteria can be illustrated utilizing the Swahili utterance:

\section{Taaluma ya isimu ina manufaa mengi.}

Translation: Linguistic discipline has many benefits.

This utterance is a locutionary act in a given sense. It includes the use and articulation, in compliance with certain grammatical laws, of linguistic forms such as phonemes, syllables, verbs, phrases and prosodic characteristics to express a certain linguistic meaning.

The Malay language is characterized by a straightforwardness of verbal expression of the language (Goddard, 1997). Assessing the verbal expressions may not necessarily reflect their real feelings or opinions and may be direct or indirect, depending on the situation and the person. For example, to claim one's self to be more co patent than others is seldom uttered in Malay culture, although the speaker may be so. Finally, the utterance establishes a connection between the speaker, the listener and the message. The speaker does not only linguistically express a context and word but also influences an event through the use of words. Thus the definitive parameters of a speech act encompass two utterance properties: a meaning in the form of a mental image that must be encoded by the speaker and a communication feature that the listener must decipher.

\subsection{Functional Grammar}

The term functional grammar has been used before, notably by Dik (1978). The study risks adding to the number of its meanings here, and thus debasing its value, only because it is peculiarly apt for this new employment that Dik (1978) proposes to outline a new grammatical formalism which, if it can be successfully developed, will be worthy of the name functional on three counts. First, it is required to function as part of a model of language production and comprehension. Secondly, the formalism ascribes to every sentence, word, and phrase. This functional description differs from the structural description of better-known formalisms mainly by stressing the function that a part plays in a whole rather than the position a part occupies in a sequence of others. Thirdly, properties that distinguish among logically equivalent sentences will have equal importance with properties that they share.

Whereas many other grammar theories consider language as an inherently arbitrary and genetically determined system, above all, FG attempts to incorporate its findings into a wider context, the theory of social interaction. Also, the proposals from the FG are evaluated against a pragmatic adequacy metric, i.e. the degree to which they are effectively consistent with 
human behaviour and interaction and account only. FG is, therefore, a reflection of the linguistic science functionalist model. It must expect complex, unstable and complex aspects. In the area of word order, for example, whether a language chooses Prefield organization (i.e. the order $\mathrm{O}$ (object) $\mathrm{V}$ (verb) or $\mathrm{O}$ postposition $\mathrm{V}$ ) or Post field organization (VO or $\mathrm{V}$ preposition $\mathrm{O}$ ) appears in itself to be immaterial for the functioning of that language. In essence, this is thus a practical matter.

On the other hand, several phenomena of word order (clause-initial placement, additional positions, passivity etc.) can be related to practical factors, such as a speaker's evaluation of the hearer's awareness and aspirations. These are also the most important phenomena of FG's adepts. There are yet other phenomena that appear to display dysfunctionality. For example, the occurrence of postpositions in a Post field language, where the language can be shown to have introduced prepositions as a 'therapeutic' measure (Kahrel, 1985).

Grammaticalisation is described as "a process focusing on how grammatical forms and constructions are formed-how they are used, and how they shape the language," based on the definition offered by Hopper \& Traugott (1993, p. 1). Grammaticalisation seems to be "a mechanism by which structure emerges from language use” (Bybee \& Hopper, 2001, p. 13).

Due to this reason, grammaticalisation is also regarded as a framework that concerns" "the problem of whether category borders are discreet and whether the structure and usage are interdependent, of the language, defined and less defined" (Hopper \& Traugott, 1993, p. 1). Within this section, this study seeks to clarify the grammaticalisation of the data from the two firms. First, Winstedt's (1927) analysis of the term is seen as an ordered listing. Essentially, FG aims to take into account the discourse structures in different contextual and communicative contexts. It is consistent with rational adequacy. The above offers the basis for describing how the linguistic concept can accurately be used for social and psychological experiences. The particular purpose of the interaction defines the meaning form to be used.

\subsection{Types of Meaning}

Semantics is an analysis of the meaning of lexical items and other language parts (Ramadhan, 2019). There are seven types of meaning; conceptual, connotative, affective, stylistics, reflected, collocative and thematic meaning. This study focuses on only two of the types of meaning: conceptual meaning and connotative meaning.

\subsubsection{Conceptual meaning}

Conceptual meaning means content that is rational, cognitive or denotable. It is based on two fundamental concepts, constructively and (in a scientific way) structures. The meanings used in dictionaries and the presentation of these lexical objects are typically derived from them (Nor \& Zamri, 2015). Moreover, the conceptual meaning of a language can be studied in terms of contrastive feature. It depends on the given lexical field (Kasriyati, Rafiah, Herdi, \& Abbas, 2019), so that (for example) the meaning of the word woman could be specified as (+ human, + adult, - male), as distinct from, man, which could be defined (+ human, + adult, + male), man is incompatible with a woman because of the distinct feature which is (male feature).

The second principle that of a structure is the principle by which larger linguistic units are built up out of smaller units, (for example) in this sentence:

$$
\left\{[(\text { All) (men) }][(\text { are })][(\text { mortal })]\}^{*}\right.
$$

*We can analyse the sentence syntactically into its constituents parts

Two linguistics concepts control semantics representation of the conceptual meaning: that of contrast and organization. These principles are comparable to the paradigmatic and syntagmatic relations; they observed in phonological and syntactic analyses. The application of these features uses a binary notation whereby the value of a feature is specified as either positive [+], negative [-] or neutral [干]. Consider these Swahili meanings: mtu 'person', mtoto 'child', mzee 'elderly person', kijana 'youth', mwanamke 'woman', mwanamume 'man', mulana 'boy', msichana 'girl'.

$$
\begin{aligned}
& \text { mtu } \rightarrow[+ \text { human }],[+ \text { - adult }],[+- \text { male }] \\
& \text { mtoto } \rightarrow[+ \text { human }],[+ \text { - adult }],[+- \text { male }] \\
& \text { mzee } \rightarrow[+ \text { human }],[+ \text { adult }],[+- \text { male }] \\
& \text { kijana } \rightarrow[+ \text { human }],[+- \text { adult }],[+- \text { male }] \\
& \text { mke } \rightarrow[+ \text { human }],[+ \text { adult }],[- \text { male }] \\
& \text { mume } \rightarrow[+ \text { human }],[+ \text { adult }],[+ \text { male }] \\
& \text { mvulana } \rightarrow[+ \text { human }],[- \text { adult }],[+ \text { male }] \\
& \text { msichana } \rightarrow[+ \text { human }],[- \text { adult }],[- \text { male }]
\end{aligned}
$$

Besides, to define the meaning, semantic features serve as a basis for comparing and contrasting lexemes. All these lexemes share the feature [+ human]. Otherwise, lexeme pairs compare or contrast on the basis of certain properties, as shown mentioned semantics rules. The application of these features uses a binary notation whereby the value of a feature is specified as either positive [+], negative [-] or neutral [干]. Consider these Malay meaning: "puan" (+human, +adult, -male), "cik" (+human, +adult,-female).

\subsubsection{Associative meaning}

The associative meaning of expression has to do with a speaker's mind. They can, in turn, be classified into six subtypes: connotative, collocative, affective, reflected and thematic. 


\subsubsection{Connotative meaning}

The communicative value an expression has by virtue of what it refers to (Leech, 1981). The connotation is the real world meaning associated with a word by a speaker. In other words, it is beyond conceptual significance and relies on background, culture or society. Connotative meaning can, therefore, be arbitrary or inconsistent. It depends on a lot how a person or society perceives a word. It is the interpretation we make with what these lexical elements represent. In English, the word 'dog' may have the connotation loyalty, apart from its referential meaning.

When evaluating word meanings, two terms called denotative or connotative meaning. It should be identified; "sea" denotes an extensive body of water, but it does contain a sense of risk, uncertainty... One element of connotative meaning is the social meaning (sometimes called stylistic meaning), which varies between ages, gender, social class and cultures. Dialect may be a strong case in point.

It is a language that speaks to the social conditions in which it is used. The pavement is used in British English and sidewalk in American English. The residence is formal, and the residence is informal.

It means that the connotative definition of a word is based on the essential conceptual characteristics to include the various additional non-criterion properties that we've come to anticipate from a comparison. It can be illustrated employing an examination of the Swahili terms: mtu 'person', mwanamume 'man' and mwanamke 'woman'. What comes to mind when you hear these expressions?

\section{Niliona mtu mmoja na wanawake wawili.}

Translation: I saw one person and two women.

Under the basic rules of language use, a woman is also a person because she has the biological characteristics of a human being. Nonetheless, some cultures do not give a woman the status of a person. In many African cultures, the meaning 'mtu' connotes a man. It is thus used exclusive of women and children. This usage is not peculiar to the elderly; the youth adopt the same attitude. Noteworthy is a popular tune which goes:

\section{Kila mtu na dame wake.}

Translation; Everyone with his dame'. What do you make of that?

And for Malay is like that. Figurative language is fundamental to Malay's oral heritage and is one the key means by which traditional bonds and attitudes are transmitted between social groups. Malaysia's complex and diverse cultural composition provides rich data for cultural, cross-cultural and intercultural study (Raslie \& Azizan, 2018). As in other cultures and communities, where communication is focused primarily on the spoken language, the use of acceptable figurative phrases is considered a characteristic of comprehension, speed-witness and education in a specific situation. Enormous importance is placed on figurative meaning both in the definition phraseological categories and in the ability to interpret figurative language:

The Malay sentence is made up of two main components: subject and predicate. Similar to English, noun sentences, verb, or adjective phrases may extract the subject and predicate (Noah, Omar \& Amruddin, 2015). The Malays stress the element kiasan (analogy, simile, metaphor, and allusion, moral) and the two lapis (layers or levels o1 meaning-i.e. the literal and the figurative) in such sayings (Winstedt, 1981).

It is the distinguishability of the image. It has earned these recurrent phraseological patterns an institutional position in society. It can be illustrated in the following examples. The phrase hidung belang to mean a ${ }^{1}$ casanova' uses the words hidung (nose) and belang (striped) as a more gentle way calling the person a ${ }^{1}$ skirt-chaser' or ${ }^{1} \mathrm{a}$ woman-chaser' the more direct way is saying it would have been kejar wanita (to chase after women). Indeed, the pattern by which a portion of a human body is connected to an adjective or a noun to indicate a certain form of action is one commonly found in Malay's two words figurative units, known as simpulan bahasa:

Mulut bocor - mouth rotten- ${ }^{1}$ someone who cannot Keep secrets'

Kepala batu-headstone- ${ }^{1}$ someone who is stubborn'

Kaki botol—foot bottle— ${ }^{1}$ an alcoholic'

Mata telinga — eye ear - ${ }^{1}$ a hope for the future'

Tangan dingin-hand cold-'someone who has 1"green fingers"'

Which demonstrate the non-compositionality of institutionalized status in figurative words in Malay. In both of these examples, awareness of the symbolic or semiotic importance of the culturally different parts of the human body is central to the figurative sense. Such cultural awareness is important to participate fully in a Malay speaking group.

When comparing English and Malay, there are some basic concepts, such as spatial relations, which share expressive meaning; for example, ${ }^{1}$ right' kanan

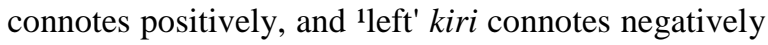
in both languages. Similarly, atas 'above' and bawah 'below' connote positively and negatively respectively in Malay as do their counterparts up and down in English. Moreover, there are also di Kerences; for example, sense data such as soft/hard and hot/cold do not necessarily share the same connotative meaning: the Malay lembut hati ('soft liver') translates better as ${ }^{1}$ Kind hearted' than ${ }^{1}$ soft hearted'- because soft has a negative connotation in English when applied to 
personality (Mastor, Jin, \& Cooper, 2000). Similarly, in English, cold-hearted has a negative connotation, whereas in Malay hati sejuk ('cold liver') has a positive connotative meaning ${ }^{1} \mathrm{a}$ feeling of relief about something'. We see this also in the Malay idiom tangan dingin - hand cold — ${ }^{1}$ to have green fingers'. In English, the word 'cool' has a positive connotation, but 'cold' does not.

\section{Conclusion}

From the results of this study, it can be concluded that there are many differences between Swahili and Malay languages. Of course, every language has a different meaning under the related culture. Each country has its own language to make it easy to communicate. There's very much the connotation meaning that is still difficult to understand. It is what requires us to continue to learn about semantics. It is observation does not mean that one type of interpretation or the other is of less importance to human communication. Instead, these significances are complementary.

However, the identification of associative-meaning next to conceptual-meaning-raises a vital query about the nature of semantics. The definition of semantics should not be limited to the transparent context. It can then be applied to implicit or symbolic verbal contact techniques. Therefore, this study argues for future studies to develop a more specific definition of semantics that would include pragmatics in its scope. The more expansive area of linguistic interpretation refers to the understanding of semantics as a crossdiscipline for several social and human disciplines, in particular: philosophy, psychology, sociology, anthropology, and computer technology.

\section{References}

Abdoolcarim, Z. (2002, September 8). 'Mahathir is Embattled': Behind the growing pressures on the PM. Asiaweek. Retrieved from http://edition.cnn.com/ASIANOW/asiaweek/m agazine/2000/0908/nat.malaysia.html

Asril, E., \& Wiza, F. (2017, December). Effectiveness of Smartphone Application for the Development of Youth Anthusiasm to Malay Culture. In IOP Conference Series: Earth and Environmental Science (Vol. 97, No. 1, p. 012007). IOP Publishing.

Bybee, J. L., \& Hopper, P. J. (2001). Frequency and the emergence of linguistic structure (Vol. 45). John Benjamins Publishing.

Cronin, B. (2016). Multiple and mixed methods research for economics. In Handbook of Research Methods and Applications in Heterodox Economics. Edward Elgar Publishing.
Derin, T., Deliani, S., Fauziah, N., Afifah, N., \& Hamuddin, B. (2019). Indonesians' Tendency to Refer Abbreviation as Acronym: Types of Abbreviation as Word Formation Process. Globish: An English-Indonesian Journal for English, Education, and Culture, 8(2).

Derin, T., Putri, N. S., Nursafira, M. S., \& Hamuddin, B. (2020). Discourse Analysis (DA) in the Context of English as a Foreign Language (EFL): A Chronological Review. ELSYA: Journal of English Language Studies, 2(1), 1-8.

Dik, S. C. (1978). Stepwise lexical decomposition. The Peter de Ridder Press.

Fontaine, R., \& Richardson, S. (2005). Cultural Values in Malaysia: Chinese, Malays and Indians Compared. Cross Cultural Management, 12(4), 63-77.

https://doi.org/10.1108/13527600510798141

Gabriel, S. P. (2014). 'After the break': reconceptualizing ethnicity, national identity and 'Malaysian-Chinese'identities. Ethnic and Racial Studies, 37(7), 1211-1224.

Goddard, C. (1997). The universal syntax of semantic primitives. Language Sciences, 19(3), 197-207.

Greimas, A. J. (1970). Les proverbes et les dictons. $D u$ sens, 1, 309-314.

Hamsa, A., \& Weda, S. (2019). Comparative Study in Indonesian and English: Identifying Linguistic Units of Comparison. Asian EFL Journal, 25(5.2), 96-110.

Hopper, P., \& Traugott. E. C. (1993). Grammaticalization (2nd ed.). Cambridge University Press.

Junaidi, J., Hamuddin, B., Simangunsong, W., Rahman, F., \& Derin, T. (2020). ICT Usage in Teaching English in Pekanbaru: Exploring Junior High School Teachers' Problems. International Journal of Advanced Science and Technology, 29(3), 5052-5063.

Kahrel, P. (1985). Indirect questions and relators. Bolkestein et al.(eds.), 165-181.

Kasriyati, D., Rafiah, S., Herdi, H., \& Abbas, M. F. F. (2019). Lexical Errors Found in Subtitling Projects of EFL Learners of University of Lancang Kuning. Lectura: Jurnal Pendidikan, 10(2), 155-166.

Kempson, R. M. (1977). Semantic theory. Cambridge University Press.

Klymenko, O. (2019). Twitterverse: The birth of new words. Proceedings of the Linguistic Society of America, 4(1), 11-1.

Leech, G. (1981). Semantics: the study of meaning: Revised and Updated: England. Pelican Books 
Mastor, K. A., Jin, P., \& Cooper, M. (2000). Malay culture and personality: A Big Five perspective. American Behavioral Scientist, 44(1), 95-111.

Mwihaki, A. (2004). Meaning as use: a functional view of semantics and pragmatics. In Swahili Forum (Vol. 11, No. 1, pp. 127-129).

Noah, S. A., Omar, N., \& Amruddin, A. Y. (2015). Evaluation of lexical-based approaches to the semantic similarity of Malay sentences. Journal of Quantitative Linguistics, 22(2), 135-156.

Nor, Z. M., \& Zamri, N. (2015). Lexical Features of Malaysian English in a Local English-Language Movie, Ah Lok Café. Procedia-Social and Behavioral Sciences, 208, 282-299.

Ozóg, A. C. K. (1993). Bilingualism and national development in Malaysia. Journal of Multilingual \& Multicultural Development, 14(1-2), 59-72.

Ramadhan, Y. (2019). An Analysis of Semantic Waves: Maton's Legitimation Code Theory for Cumulative Knowledge-Building. ELSYA: Journal of English Language Studies, 1(2), 3944.

Raslie, H. B., \& Azizan, A. B. (2018). Refusals in the Malay Culture: Gender Differences in Focus. International Journal of Academic Research in Business And Social Sciences, 8(12).

Sapir, E., \& Mandelbaum, D. G. (1956). Culture, Language and Personality. Selected Essays Edited by David G. Mandelbaum. University of California Press.

Stigand, C. H. (2013). Dialect in Swahili: A Grammar of Dialectic Changes in the Kiswahili Language. Cambridge University Press.

Winstedt, R. (1981). The Malays: A cultural history. Three Continents. Amazon

Winstedt, R. O. (1927). The great flood, 1926. Journal of the Malayan Branch of the Royal Asiatic Society, 5(2 (100), 295-309.

Zook, K. L., \& Pearce, J. H. (2018). Quantitative descriptive analysis. In Applied Sensory Analy of Foods (pp. 43-71). Routledge. 